\title{
Androgen receptor signaling pathways as a target for breast cancer treatment
}

\author{
Elisabetta Pietri', Vincenza Conteduca1, Daniele Andreis², Ilaria Massa2, \\ Elisabetta Melegari', Samanta Sarti', Lorenzo Cecconetto', Alessio Schirone1, \\ Sara Bravaccini³, Patrizia Serra², Anna Fedeli1, Roberta Maltoni', Dino Amadori', \\ Ugo De Giorgi' and Andrea Rocca'
}

'Department of Medical Oncology, Istituto Scientifico Romagnolo per lo Studio e la Cura dei Tumori (IRST) IRCCS, Meldola, Forlì-Cesena, Italy

2Unit of Biostatistics and Clinical Trials, Istituto Scientifico Romagnolo per lo Studio e la Cura dei Tumori (IRST) IRCCS, Meldola, Forlì-Cesena, Italy

${ }^{3}$ Biosciences Laboratory, Istituto Scientifico Romagnolo per lo Studio e la Cura dei Tumori (IRST) IRCCS, Meldola, Forlì-Cesena, Italy
Correspondence should be addressed to I Massa or A Rocca Email

ilaria.massa@irst.emr.it or andrea.rocca@irst.emr.it

\begin{abstract}
The androgen receptor (AR) is a ligand-dependent transcription factor, and its effects on breast range from physiological pubertal development and age-related modifications to cancer onset and proliferation. The prevalence of AR in early breast cancer is around $60 \%$, and AR is more frequently expressed in ER-positive than in ER-negative tumors. We offer an overview of AR signaling pathways in different breast cancer subtypes, providing evidence that its oncogenic role is likely to be different in distinct biological and clinical scenarios. In particular, in ER-positive breast cancer, AR signaling often antagonizes the growth stimulatory effect of ER signaling; in triple-negative breast cancer (TNBC), AR seems to drive tumor progression (at least in luminal AR subtype of TNBC with a gene expression profile mimicking luminal subtypes despite being negative to ER and enriched in AR expression); in HER2-positive breast cancer, in the absence of ER expression, AR signaling has a proliferative role. These data represent the rationale for AR-targeting treatment as a potentially new target therapy in breast cancer subset using androgen agonists in some AR-positive/ER-positive tumors, AR antagonists in triple-negative/ AR-positive tumors and in combination with anti-HER2 agents or with other signaling pathways inhibitors (including PI3K/MYC/ERK) in HER2-positive/AR-positive tumors. Only the ongoing and future prospective clinical trials will allow us to establish which agents are the best option in every specific condition, keeping in mind that there is evidence of opposite androgens and AR agonist/antagonist drug effects on cell proliferation particularly in AR-positive/ER-positive tumors.
\end{abstract}

\section{Key Words}

- androgen receptor

breast cancer

- androgen receptor structure

- signaling pathway

- AR-targeting therapy

\section{Introduction}

\section{AR receptor structure and signaling}

The androgen receptor (AR) is a member of the steroid hormone receptor family that in turn belongs to the superfamily of nuclear receptors. Other steroid hormone receptors include estrogen receptor (ER), glucocorticoid receptor (GR), progesterone receptor (PR) 
and mineralocorticoid receptor. AR is a ligand-dependent transcription factor that controls the expression of specific genes involved in many physiological and pathological processes (Mangelsdorf et al. 1995, Higa \& Fell 2013). The receptor exerts an influence on pubertal development of primary and secondary sexual traits (including mammary gland in males and females); levels of mental energy, libido and muscle strength; and overall well-being of men and women in adulthood and male fertility and is involved in the onset of prostate and breast cancers (BCs).

The human AR gene is located on the long arm of the $\mathrm{X}$ chromosome, q11-12, and comprises eight exons: exon 1 encodes for N-terminal domain (NTD), exons 2 and 3 encode for DNA-binding domain (DBD), exon 4 encodes for hinge region and the remaining four exons encode for the ligand-binding domain (LBD) (Higa \& Fell 2013).

Analysis of different AR domains reveals several structures and functions: (1) LBD binds to specific steroid ligands (agonists or antagonists). Activation function-2 (AF2) is an activation domain located within the LBD, through its interaction with co-regulatory factors, facilitating transcriptional processes by interacting with chromatin; (2) DBD includes eight cysteine residues that form two coordination complexes, each composed of four cysteines and a zinc ion (proximal box region (P-box) and distal box region (D-box)). P-box is crucial for recognition and binding of DNA response element, whereas D-box mediates dimerization of the receptor on the DNA; (3) a hinge region links DBD and LBD and is responsible for nuclear localization; and (4) NTD interacts with LBD and co-activators, initiating selective gene activation. The activation function-1 (AF1) activation domain, located within NTD, binds specific co-activators that facilitate the assembly of the transcription initiation complex (Kumar \& McEwan 2012).

AR has a dynamic mechanism of action defined as a transcriptional or genomic mode of action that develops in subsequent steps. In the absence of the hormone, the receptor is nevertheless present in the cytoplasm in a heterocomplex with heat-shock proteins and immunophilins (chaperone complex). Molecular chaperones, for example, heat-shock protein 90 (HSP90), assist protein folding by maintaining AR in high-affinity ligand-binding conformation to facilitate response to specific ligands.

Binding with the hormone leads to a rearrangement in $\mathrm{LBD}$, inducing translocation to the nucleus and binding with co-regulatory factors through the AF2 region. It also results in rearrangement in the NTD, which influences AR transcriptional activity. The DBD allows recognition/binding of DNA androgen response element (ARE) and dimerization of receptor on DNA, which leads to an AR-transcription complex with transcriptional activity through NTD-LBD interaction. After completing its molecular activity, the ARtranscription complex is rapidly dissociated and recycled to the cytoplasm through chaperone intervention. AR is also subject to posttranscriptional modifications such as phosphorylation, particularly in serine, threonine and tyrosine residues present in each of the major protein domains. These posttranscriptional modifications (in combination with other modifications such as ubiquitination and methylation) act as an allosteric regulation fine-tune of receptor structure and function (Kumar \& McEwan 2012, Koryakina et al. 2014).

Of note, the principal AR domains are unstructured regions termed "intrinsically disordered", which undergo disorder/order transition by conformational changes under specific conditions. The disorder/order transition in the AR protein permits highly specific interactions with several ligands but also low-affinity, easily reversible molecular interactions (Kumar \& McEwan 2012), both useful for proteins such as AR involved in signaling and transcriptional regulation.

In addition to the previously mentioned transcriptional/genomic mode of action, there is an increasing body of evidence to suggest the existence of a non-transcriptional/non-genomic mode of AR action. Such a mechanism does not require receptor-DNA binding or RNA synthesis but involves the induction of conventional second-messenger signal transduction cascades to modulate AR activity.

Prostate cancer cells show a proliferative response to androgens within minutes, which is too rapid a time to involve changes in transcription and protein synthesis. This response can be attributed to the rapid induction of conventional second messengers in non-transcriptional/ non-genomic AR signaling (Heinlein \& Chang 2002, Liao et al. 2013) and is probably also active in BC.

Non-transcriptional/non-genomic AR signaling may occur in an ERK-dependent or ERK-independent manner. ERK-mediated non-transcriptional/non-genomic AR signaling is mediated by cytoplasmic AR and interacts with phosphoinositide 3-kinase (PI3K), Src family kinase and Ras GTPase. In turn, these converge on the MAPK/ERK pathway with subsequent ERK translocation in the nucleus and interaction with transcriptional factors (TFs) regulating the expression of genes involved in cell proliferation. Moreover, in response to androgens, membranebound AR or plasma membrane $G$ protein-coupled

Published by Bioscientifica Ltd 
receptors (GPCRs) or sex hormone-binding globulin receptor (SHBGR) upregulates cyclic adenosine monophosphate (cAMP) levels, modulating $\mathrm{Ca}^{2+}$ intracellular concentration and activating protein kinase C (PKC), which converges on MAPK/ERK pathway (Simoncini \& Genazzani 2003, Li \& Al-Azzawi 2009, Liao et al. 2013) (Fig. 1).

Non-ERK-mediated non-transcriptional/non-genomic AR signaling is mediated by several pathways: the mammalian target of rapamycin (mTOR) phosphorylation (with consequent activation) by cytoplasmic AR/PI3K interaction; forkhead box protein O1 (FOXO1) phosphorylation and consequent inactivation of its apoptotic signaling by cytoplasmic AR/PI3K interaction or direct interaction of cytoplasmic AR with FOXO1; protein kinase A (PKA) activation by membrane-bound AR/GPCRs/SHBGR and subsequent $\mathrm{Ca}^{2+}$ intracellular concentration modulation. Activated mTOR and PKA and inactivated FOXO1 lead to increased cell proliferation (Li \& Al-Azzawi 2009, Liao et al. 2013, Simoncini \& Genazzani 2013) (Fig. 2).

Transcriptional/genomic and non-transcriptional/ non-genomic AR signaling are not independent, a cross talk existing between these two pathways because ERK (involved in non-transcriptional/non-genomic AR signaling) enhances AR transcriptional activity (transcriptional/genomic pathway) through direct phosphorylation of AR and its co-regulators. This loop represents a non-genomic mechanism of control of AR transcriptional activity, which is capable of generating an increased response to androgenic stimulation (Liao et al. 2013) (Fig. 3). Moreover, the capacity of SHBG and GPCR to modulate $\mathrm{Ca}^{2+}$ intracellular concentration, activating PKC and PKA, permits cell proliferation even at very low levels of androgens (Liao et al. 2013). The existence of cross talk between transcriptional/genomic and nontranscriptional/non-genomic AR signaling must be taken into account in breast and prostate cancer treatment. In particular, non-genomic AR activity in $\mathrm{BC}$ represents a mechanism of resistance to anti-androgenic therapy currently under evaluation in AR-driven subtypes.

\section{AR signaling effects in $B C$}

$\mathrm{AR}$ expression in $\mathrm{BC}$ varies based on the cutoff used to define AR positivity. In a systematic review of 19 studies on a total of 7693 women with early BC, AR expression was documented in $60.5 \%$ of patients and was more frequent in ER-positive tumors (74.8\%) than in ER-negative tumors (31.8\%) (Vera-Badillo et al. 2014). The same meta-analysis showed that AR expression in early BC was associated with improved overall survival (OS) and disease-free survival (DFS) both in ER-positive and in ER-negative tumors (Vera-Badillo et al. 2014). These results were confirmed after addressing minor inconsistencies with data from the original articles (Ocana et al. 2015, Wang \& Yang 2015). A recent meta-analysis by Kim et al. confirmed these data, reporting longer DFS and OS in patients with AR expression than in those without (Kim et al. 2015). Another metaanalysis indicated a low risk of cancer recurrence in all BC

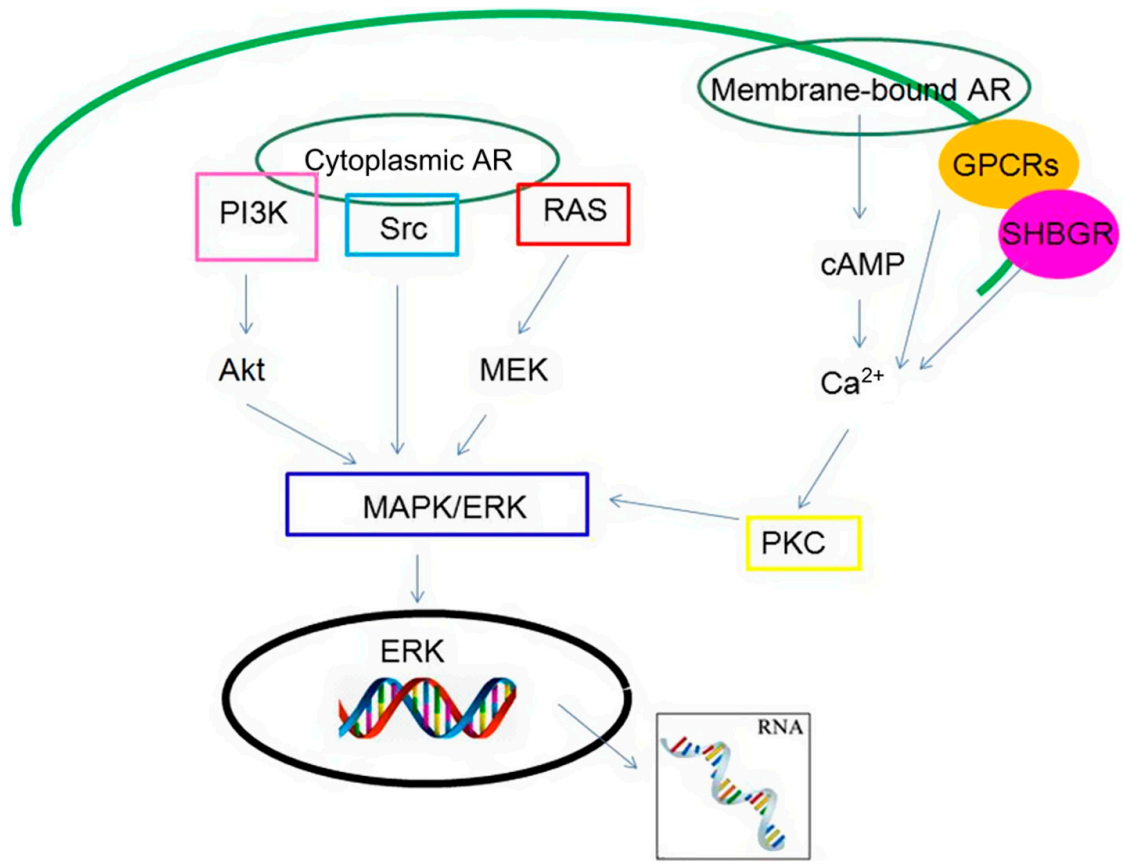

Figure 1

ERK-mediated non-transcriptional/non-genomic AR signaling. (1) Left, cytoplasmic AR interacts with phosphoinositide 3-kinase (PI3K), Src family kinase and Ras GTPase, which in turn converge on MAPK/ERK pathway with subsequent ERK translocation into the nucleus and induction of genes involved in cell proliferation. (2) Right, membrane-bound AR or plasma membrane $G$ protein-coupled receptors (GPCRs) or sex hormone-binding globulin receptor (SHBGR) upregulates cyclic adenosine monophosphate (CAMP) levels, modulating $\mathrm{Ca}^{2+}$ intracellular concentration activating protein kinase C (PKC), which converges on the MAPK/ERK pathway. http://erc.endocrinology-journals.org DOI: 10.1530/ERC-16-0190
C 2016 Society for Endocrinology Printed in Great Britain 


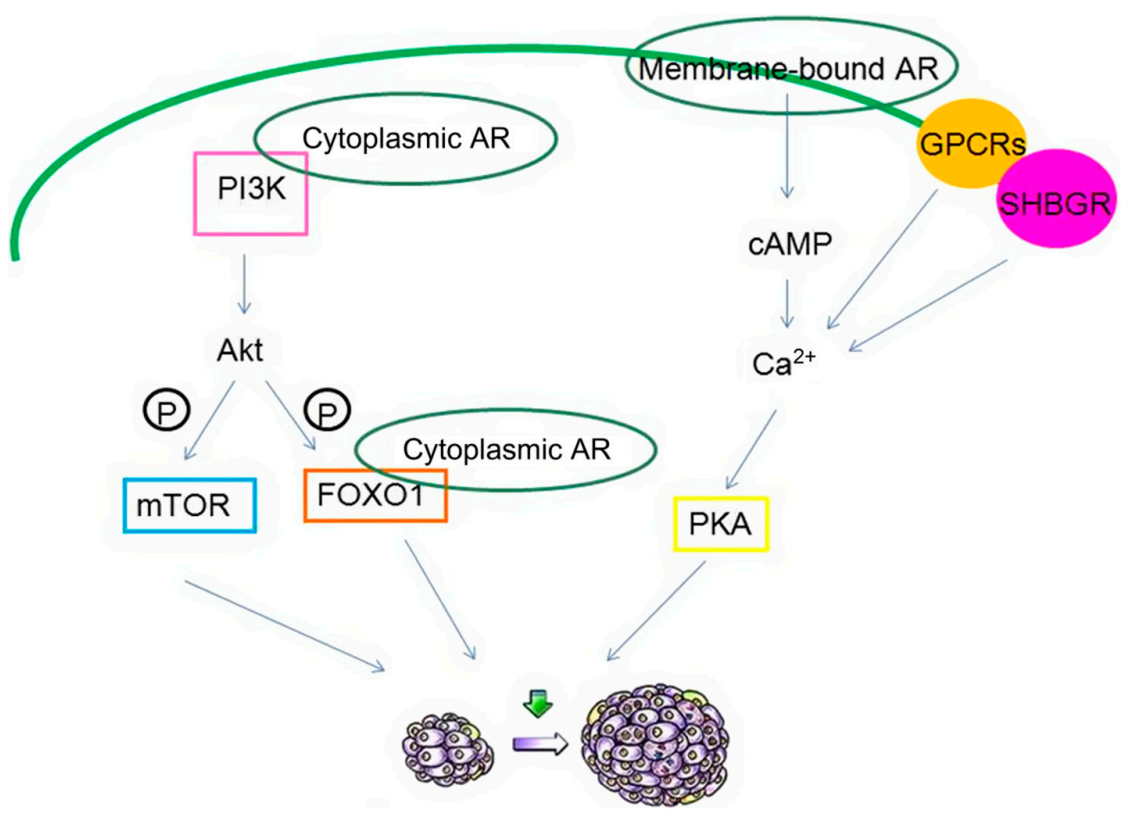

Figure 2

Non-ERK-mediated non-transcriptional/ non-genomic AR signaling. (1) Left, cytoplasmic $A R / P I 3 K$ interaction induces mammalian target of rapamycin (mTOR) phosphorylation (and consequent activation) and forkhead box protein O1 (FOXO1) phosphorylation (and consequent inactivation). A direct interaction of cytoplasmic AR with FOXO1 also induces its phosphorylation and consequent inactivation. (2) Right, membrane-bound AR/GPCRs/SHBGR, through $\mathrm{Ca}^{2+}$ intracellular concentration modulation, activate protein kinase A (PKA). Activated mTOR and PKA and inactivated FOXO1 lead to increased cell proliferation. subtypes expressing AR and improved OS in ER-positive BCs expressing AR ( $Q u$ et al. 2013). Conversely, some studies did not report a better outcome (Park et al. 2011) or observed an even poorer prognosis (Choi et al. 2015) in AR-positive/ER-negative BC. Although these controversial results are probably partly related to the use of different antibodies with variable affinities against AR and different scoring systems and cutoff values for the estimation of AR expression, the prognostic role of AR may, in actual fact, change in different $\mathrm{BC}$ subtypes.

AR expression has also been shown to influence response to neoadjuvant chemotherapy, albeit also here with some contradictory results, even among the larger studies considered here. In the retrospective analysis of the GeparTrio phase III study (Loibl et al. 2011), evaluating neoadjuvant treatment with docetaxel, doxorubicin and cyclophosphamide (TAC) for six versus eight cycles in early (after two cycles) responders and comparing TAC with capecitabine plus vinorelbine in early non-responders, on 673 (out of 2357 total) patients with assessable pre-treatment core biopsies, the total pathological complete response (pCR) rate was significantly higher in immunohistochemically AR-negative cases than in AR-positive cases $(25.4 \%$ vs $12.8 \%, P<0.0001)$, and AR

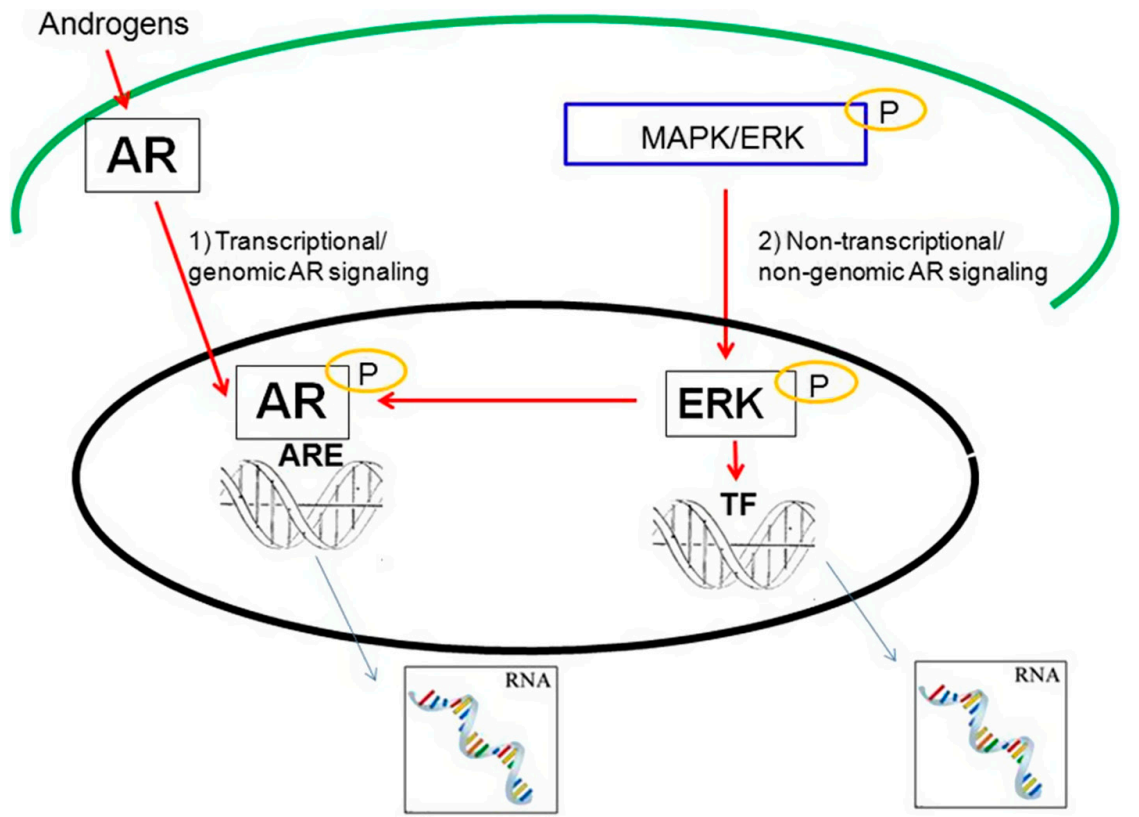

Figure 3

Cross talk between genomic and non-genomic pathways. ERK enhances AR transcriptional activity (transcriptional/genomic pathway) through direct phosphorylation of AR and its co-regulators. 
was an independent predictor of pCR, but patients with AR-negative tumors had worse DFS and OS at univariate analysis, although AR was not an independent prognostic factor at multivariate analysis. In the subgroup of 111 patients with TNBC, AR expression was rarer than in other subtypes and was not associated with pCR, but conferred a better DFS and OS, whereas among the other subtypes AR expression was inversely related to $\mathrm{PCR}$ in ER-positive, HER2-negative tumors, but did never affect prognosis. The negative prognostic impact of the lack of AR was evident particularly in patients not achieving a pCR and not in those achieving pCR. In a study on 130 patients treated with neoadjuvant sequential taxane and anthracyclinebased chemotherapy for TNBC, the TNBC subtype was defined on the basis of gene expression profiling according to Lehmann et al. 2011. This subtype was found to be an independent predictor of $\mathrm{pCR}(P=0.022)$, with $\mathrm{pCR}$ rates higher in the basal-like $1(52 \%)$ and lowest in the basal-like 2 (0\%) and LAR (10\%) subtypes (Masuda et al. 2013), whereas the LAR subtype showed the best survival outcomes, although these were not statistically significant due to the limited sample size. A more recent work on 177 patients treated with neoadjuvant fluorouracil, doxorubicin and cyclophosphamide for four cycles followed by 12 courses of weekly paclitaxel confirmed a less frequent expression of $\mathrm{AR}$ in TNBC and a negative effect of AR positivity on the rate of pCR among TNBC cases, but showed a negative effect of AR positivity also on DFS among patients with TNBC (Asano et al. 2016).

The real prognostic role of AR in $\mathrm{BC}$ can only be understood by evaluating AR oncogenic function in different BC subtypes.

The signaling effect of AR depends on its interaction with ER signaling (Chia et al. 2015) because a cross talk exists between these two receptors (Fioretti et al. 2014). In particular, we can analyze AR biology in three different BC subtypes: ER-positive BC, HER2-positive $\mathrm{BC}$ and triplenegative $\mathrm{BC}$ (TNBC). In ER-positive $\mathrm{BC}$, AR signaling often antagonizes the growth stimulatory effect of ER signaling. Several mechanisms have been hypothesized for this antiproliferative effect (Lim et al. 2012, 2014, Chia et al. 2015): (1) AR directly inhibits ER target genes; (2) AR competes with ER for binding on estrogen response elements (ERE), preventing ER-dependent gene transcription; (3) AR binds and sequesters TFs that are no longer available for ER gene transcription; (4) AR upregulates ER $\beta$ receptors. ER $\beta$ exerts a growth and invasion inhibitory action on ER $\alpha$-positive BC cells through ER $\beta$ inhibition of selective ER $\alpha$ gene expression (Rizza et al. 2014). ARE is a short sequence of DNA located in the human ER $\beta$ gene promoter and thus
AR binding to ARE upregulates these receptors; and (5) AR induces apoptosis through direct downregulation of cyclin D1 gene expression (Lanzino et al. 2010). Nonetheless, some ER-positive BC cell lines, such as MCF-7 and MDA-MB-453, are growth stimulated by androgens and inhibited by anti-androgens (Birrell et al. 1995, Cochrane et al. 2014). Other data show a proliferative response of ER-positive BC cell lines to adrenal androgens (Poulin \& Labrie 1986, Najid \& Habrioux 1990, Boccuzzi et al. 1992, Maggiolini et al. 1999, Billich et al. 2000).

TNBC (ER/PR-negative and HER2-negative) can be divided into different subtypes on the basis of the gene expression signature, that is, basal-like 1 and 2 subtypes enriched in cell cycle and DNA damage response components and pathways; immunomodulatory subtype enriched for gene ontologies in immune cell processes; mesenchymal and mesenchymal stem-like subtypes enriched in components and pathways involved in cell motility, epithelial-mesenchymal transition and growth factor pathways; luminal AR (LAR) subtype (previously characterized as molecular apocrine subtype) with a gene expression profile mimicking luminal subtypes despite being ER-negative and enriched in hormonally regulated pathways including steroid synthesis (high AR expression) (Lehmann et al. 2011, Barton et al. 2015).

Preclinical data suggest that AR drives tumor progression in some subtypes of TNBC (Barton et al. 2015, Chia et al. 2015). In particular, in vitro studies show that AR activation can reduce chemotherapy efficacy in LAR subtype through the AR-mediated transcriptional regulation of pro- and anti-apoptotic genes (Pang et al. 2006), suggesting the usefulness of an AR block combined with chemotherapy in this setting (Kach et al. 2015).

In HER2-positive $\mathrm{BC}$, in the absence of ER expression, there is strong evidence of a proliferative role of AR signaling (Chia et al. 2015). Preclinical data would seem to suggest an oncogenic role of AR in ER-negative HER2-positive BC: (1) AR directly upregulates WNT7B expression, leading to WNT/ßCATENIN activation. Nuclear translocation of activated $\beta$-CATENIN, in cooperation with AR, stimulates HER3 gene transcription. Subsequently, HER3 forms heterodimers with HER2 and modulates the PI3K/AKT pathway, promoting cell proliferation (Ni et al. 2011), resulting in a positive feedback loop between AR and HER2/HER3 signaling pathways; (2) AR, via PI3K/AKT activation by HER2/HER3 heterodimers, phosphorylates MAD1 (a MYC transcriptional repressor), promoting its degradation and dissociation from MAX (the obligatory partner of MYC). Without MAD1 competition, MYC

Published by Bioscientifica Ltd 
forms heterodimers with MAX that sequentially access transcriptional sites in a cell proliferation direction (Zhu et al. 2008, Ni et al. 2013); (3) AR induces dissociation of repressor transcription factor 7-like 2 (TCF7L2) from the pioneer transcription factor of AR, FOXA1, promoting AR target gene MYC transcription with mitogenic action (Ni et al. 2013). There is a positive feed-forward loop involving MYC in the regulation of androgendependent transcription in ER-negative HER2-positive BC subtype; (4) AR induces ErbB2 expression, which activates ERK. ERK activation, in turn, promotes cAMP response element-binding protein activity, inducing AR expression and creating an ERK-AR-positive feedback loop (Chia et al. 2011) (Fig. 4).

A plethora of genes are targeted by AR (Jiang et al. 2009), but knowledge on their roles in different BC subtypes is limited. Highly expressed in the LAR subtype of TNBC are genes involved in fatty acid and lipid synthesis, steroid synthesis, porphyrin metabolism and androgen/estrogen metabolism. These include numerous downstream AR targets and co-activators (DHCR24, ALCAM, FASN, FKBP5, APOD, PIP, SPDEF and CLDN8) and luminal genes such as FOXA1, KRT18 and XBP1 (Lehmann et al. 2011). An investigation of the AR-transcriptional network in a large cohort of $\mathrm{BC}$ cell lines representative of different BC subtypes showed enrichment for genes involved in cell-cycle regulation and mitosis; glucose, protein and nucleoside metabolism; and oxygen homeostasis (Naderi 2015). The subset of 35 most highly correlated genes defining an "AR gene signature" included
F7 (encoding coagulation factor VII, potentially linking AR to thromboembolic episodes) and transcriptional regulators such as PATZ1 (encoding a co-regulator of AR), NFATC4 (encoding a member of nuclear factors of DNAbinding transcription complex in activated T cells, NFAT) and SPDEF (encoding a protein that belongs to the ETS family of transcription factors), all of which have been implicated in prostate cancer (some of them could be co-expressed with AR due to a common transcriptional regulatory mechanism, and not directly induced by $\mathrm{AR}$ ).

It is logical to consider $\mathrm{AR}$ as a target for $\mathrm{BC}$ treatment. The challenge is to identify the correct way in which to target AR in order to inhibit proliferation. This review provides the rationale and data for the use of $A R$ antagonists and $\mathrm{AR}$ agonists in different $\mathrm{BC}$ subtypes.

\section{AR-targeting therapy in BC}

Evidence of a benefit from androgens in patients with advanced breast carcinoma was first reported in 1939 by Ulrich and Loeser (Ulrich 1939, Loeser 1939) using testosterone propionate and confirmed a few years later by Fels and Frank (Fels 1944, Frank \& Heeemann 1946). Subsequently, the use of testosterone propionate, the testosterone derivative fluoxymesterone and the steroid calusterone obtained promising results in terms of disease response and pain relief in patients with metastatic BC (MBC) whose hormone receptor status was unknown (Segaloff et al. 1951, Kennedy 1958, Goldenberg 1964, Goldenberg et al. 1973, Gordan et al. 1973). More recently,
A

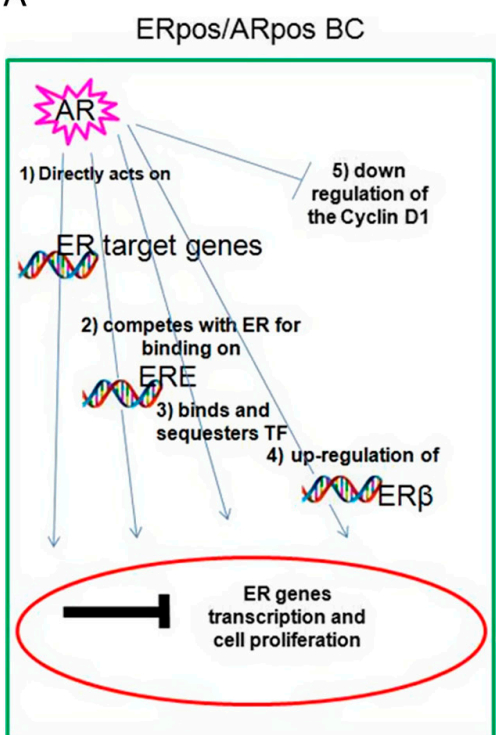

B

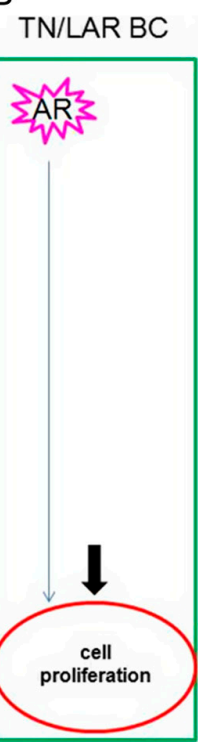

C ERneg/HER2pos/ARpos BC

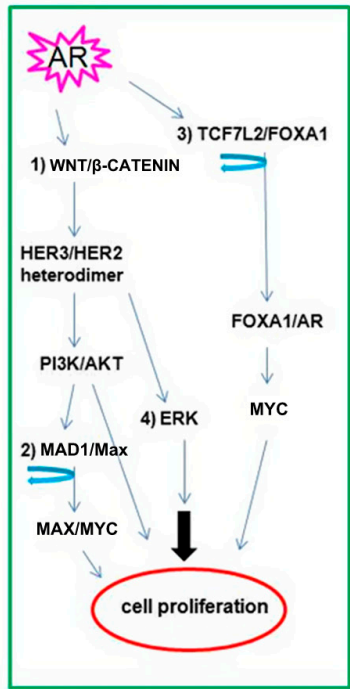

Figure 4

AR signaling effects in breast cancer subtypes. (A) ER-positive/AR-positive breast cancer: (1) AR directly inhibits $E R$ target genes. (2) AR competes with ER for binding on ERE. (3) AR binds and sequesters TF. (4) AR upregulates ER $\beta$ receptors. (5) $A R$ induces direct downregulation of cyclin D1 gene expression. (B) TN/LAR BC: AR drives tumor progression.

(C) ERneg/HER2pos/ARpos BC: (1) AR directly upregulates WNT7B, which acts on WNT/ $\beta$ CATENIN, stimulating HER3 gene transcription with subsequent HER3/HER2 heterodimerization and modulation of PI3K/AKT pathway. (2) HER2/ HER3 heterodimers activate PI3K/AKT pathway, which phosphorylates MAD1, promoting its degradation and dissociation from Max with subsequent MYC-MAX heterodimerization and access to transcriptional sites. (3) AR induces dissociation of repressor transcription factor 7-like 2 (TCF7L2) from the pioneer transcription factor of AR, FOXA1, promoting AR target gene MYC transcription. (4) AR induces ErbB2 expression, which activates ERK with consequent cell proliferative effect. 
Boni et al. reported a significant therapeutic activity of testosterone propionate in a consecutive series of 53 patients with ER/PgR-positive MBC (Boni et al. 2014). Disease regression was observed in $17 \%$ of patients, with a median survival of 12 months, calculated from the first day of testosterone administration to the last day of follow-up or date of death.

Testosterone, delivered by subcutaneous implant alone or in combination with anastrozole to treat symptoms of hormone deficiency in menopausal women, has been shown to reduce BC incidence (Glaser \& Dimitrakakis 2015). The same combination also proved safe in $72 \mathrm{BC}$ survivors, among whom no cases of recurrent disease were registered (Glaser \& Dimitrakakis 2015). Moreover, it showed anti-tumor activity when administered as neoadjuvant therapy through intramammary peritumoral implants in BC patients with positive hormone receptor (ER, PgR and AR) BCs (Glaser \& Dimitrakakis 2015).

Given the recent important findings about AR in BC, especially that of its change in role when ER expression is present, the most logical rationale for targeting AR with agonists or antagonists is to first analyze $\mathrm{BC}$ subtypes.

\section{AR-targeting therapy in ER-positive/AR-positive BC}

The inhibitory effect of AR on ER activity seen in several in vitro $\mathrm{BC}$ models indicates that we can consider androgens and AR modulators as a cancer treatment for ER/AR-positive subtype. DHEA (an androgen precursor) and 4-OH-testosterone are currently under evaluation. A phase II study (NCT02000375) is currently ongoing at our Institute (IRST IRCCS) to investigate the safety and activity of a combination of DHEA and an aromatase inhibitor in pre-treated postmenopausal patients with ER/PgR-negative/HER2-negative/AR-positive and ER and/or PgR-positive/HER2-negative/AR-positive MBC. The DHEA-aromatase inhibitor combination has the aim of preventing DHEA conversion into estrogens, thus nullifying their proliferative effect in ER-positive tumors and maximizing the amount of androgens available. We also decided to enroll LAR TNBC patients on the basis of the combination's proven downregulatory effect on the growth of ER-negative/ AR-positive BC cell lines (Nahleh 2008). Enrolment of the ER and/or PgR-positive/HER2-negative/AR-positive cohort of patients has been completed, whereas that of the ER/PgR-negative/HER2-negative/AR-positive cohort has been stopped because of slow recruitment and also recent data showing a greater likelihood of benefit from anti-androgen agents.
Transdermal CR1447 (4-OH-testosterone) is currently under evaluation in a phase II first-in-human trial of patients with endocrine-responsive HER2-negative and triple-negative/AR-positive metastatic or locally advanced BC (NCT02067741).

Enobosarm is an androgen agonist without estrogenic properties and with a reduced capacity for androgenization or virilization (Coss et al. 2014). In a phase II study conducted by Overmoyer et al., six out of 17 patients with ER-positive, AR-positive MBC had disease stabilization for longer than 6 months and showed good treatment tolerability (Overmoyer 2015). Androgen inhibitors have also been evaluated in ER-positive BC because they are capable of decreasing both androgen and estrogen syntheses via the inhibition of cytochrome P450 (CYP)17A1 (also known as cytochrome P450c17, an enzyme with both 17-alpha-hydroxylase and 17,20-lyase activities with a key role in the steroidogenic pathways producing progestins, mineralocorticoids, glucocorticoids, androgens and estrogens).

Abiraterone acetate (AA) irreversibly inhibits CYP17A1 and has been used in phase I/II trials on postmenopausal ER-positive/AR-positive and ER-negative AR-positive MBC. Preliminary results show the suppression of circulating estradiol and androgen levels and a clinical benefit of $21 \%$ at 24 weeks in the $\mathrm{ER}+/ \mathrm{AR}+$ group with good tolerability (Ng et al. 2012). A phase I/II trial studying the side effects and optimal dose of AA together with its mechanisms of action is currently ongoing in postmenopausal women with ER-positive and any AR status vs AR-positive and ER-negative advanced or MBC (NCT00755885).

Orteronel is a non-steroidal androgen inhibitor suppressing 17,20-lyase enzyme activity, critical for androgen production. At present, it is under evaluation as monotherapy in patients with AR-expressing $\mathrm{MBC}$ (NCT01990209).

Resistance to conventional endocrine treatment is an obstacle in treating ER-positive/AR-positive BC. Preclinical data have shown that AR overexpression may induce tamoxifen resistance (Peters et al. 2009) and that antagonism of AR may restore tamoxifen sensitivity by inhibiting the ER agonist response of tamoxifen (De Amicis et al. 2010). In patients with ER-positive BCs, a high AR:ER $(\geq 2.0)$ ratio has been shown to be associated with a greater than four-fold increased risk of failure while on tamoxifen $(\mathrm{HR}=0.43)$ and is also an independent predictor of diseasefree and disease-specific survival (Cochrane et al. 2014). Conversely, in other studies, AR expression has been found to be associated with good response to tamoxifen

Published by Bioscientifica Ltd 
(Park et al. 2012) and to have no correlation with benefit from adjuvant tamoxifen (Hilborn et al. 2016).

The role of $\mathrm{AR}$ in aromatase inhibitor-resistant $\mathrm{BC}$ is even less clear. O'Shaughnessy et al. recently demonstrated that AA used in combination with exemestane in pre-treated ER-positive MBC patients did not improve outcome compared with treatment with exemestane alone, probably due to AA-induced increased progesterone synthesis (O'Shaughnessy et al. 2016). Further research is needed to understand whether the use of AR antagonist is indicated in ER-positive/AR-positive $\mathrm{BC}$ that is resistant to aromatase inhibitors.

Of interest, the anti-androgen enzalutamide has been shown to inhibit estradiol-mediated proliferation of ER-positive/AR-positive BC cell lines and also to inhibit 5-alpha-dihydrotestosterone (DHT)-driven tumor growth in both ER-positive/AR-positive (MCF7) and ER-negative/ AR-positive (MDA-MB-453) xenografts (Cochrane et al. 2014). A study evaluating safety, tolerability and pharmacokinetics of enzalutamide alone or in combination with anastrozole, exemestane or fulvestrant in patients with incurable BC is ongoing (NCT01597193).

\section{AR-targeting therapy in triple-negative/LAR BC}

As AR in TNBC, especially in the LAR subtype, has the functional role of maintaining cell proliferation, the use of AR antagonists seems a logical choice in the treatment of this subtype. Bicalutamide, an oral non-steroidal antiandrogen that competitively inhibits the binding of androgens with AR, has shown a proof-of-principle for the efficacy of minimally toxic androgen blockade in a select group of patients with ER/PgR-negative, AR-positive BC (Gucalp et al. 2013). One case of complete response to bicalutamide was recently reported in a patient with metastatic triple-negative, AR-positive BC (Arce-Salinas et al. 2016).

Enzalutamide is another non-steroidal anti-androgen with a five-fold greater affinity for the AR than bicalutamide but without its partial AR agonist properties (this is because enzalutamide, unlike bicalutamide, is capable of reducing the efficiency of its nuclear translocation and of impairing both DNA binding to AREs and recruitment of co-activators) (Tran et al. 2009). Preliminary results from a safety and efficacy study of enzalutamide in 75 evaluable patients with advanced AR-positive TNBC showed a clinical benefit of $35 \%$ at 16 weeks, with an $8 \%$ objective response rate. An androgen-driven gene signature predicting responsiveness was identified (Traina et al. 2015).
Cyclin-dependent kinase 4 and 6 inhibitors, such as palbociclib, have shown activity in enzalutamideresistant prostate cancer preclinical models with $\mathrm{AR}$ F876L point mutation (Korpal et al. 2013), showing the potential to reverse resistance to anti-androgens. Indeed, the activity of palbociclib has also been demonstrated in some TNBC cell lines, belonging to the LAR and the mesenchymal stem-like subtypes (Asghar et al. 2015), in which sensitivity was associated with AR expression.

Other new agents are undergoing evaluation as AR antagonists. In particular, LDB-directed drugs, after binding to $\mathrm{AR}$, prevent $\mathrm{AR}$ nuclear translocation and its binding to ARE, whereas chaperone protein (e.g., HSP90) inhibitors arrest protein folding, maintaining AR in highaffinity ligand-binding conformation (Proverbs-Singh et al. 2015).

In particular, STA-9090 (a HSP90 inhibitor) is currently being evaluated in TNBC and ER-positive, HER2positive BCs (NCT01273896, NCT01677455). AA, capable of reducing androgen production, is being studied in molecular apocrine BC (NCT01842321).

In 2006, the International Breast Cancer Study Group reported a detrimental effect of adjuvant tamoxifen within an ER-negative cohort of BC patients (International Breast Cancer Study Group, et al. 2006), an event potentially related to AR overexpression in this group of TNBC patients with non-genomic AR signaling activation. A recent re-appraisal of results from an old randomized trial of adjuvant tamoxifen versus no endocrine therapy in patients with node-negative early BC showed that tamoxifen was detrimental in patients with AR-negative TNBC but improved outcome in patients with AR-positive TNBC (Hilborn et al. 2016). Such opposing results on the effect of tamoxifen in AR-expressing TNBC underline that we still do not know all the effects that androgen exerts on different $\mathrm{BC}$ subtypes with different hormonal scenarios.

\section{AR-targeting therapy in ER-negative/HER2-positive BC}

Given the confirmed interaction between AR and HER2, the most logical therapeutic approach to this subtype is the combination of anti-HER2 and anti-AR treatments. A study evaluating the efficacy and safety of enzalutamide with trastuzumab in HER2-positive/AR-positive metastatic or locally advanced BC is currently ongoing (NCT02091960). The multiple inhibition of AR and other signaling pathways (including PI3K/MEK/WNT/MYC/ cell-cycle regulators) could also be useful in this subtype (Proverbs-Singh et al. 2015) (Table 1).

Published by Bioscientifica Ltd. 


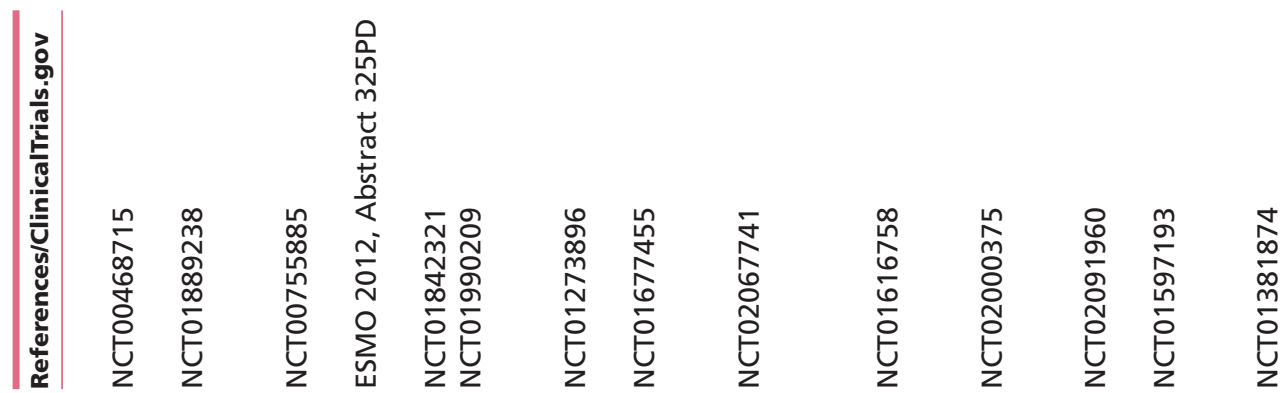
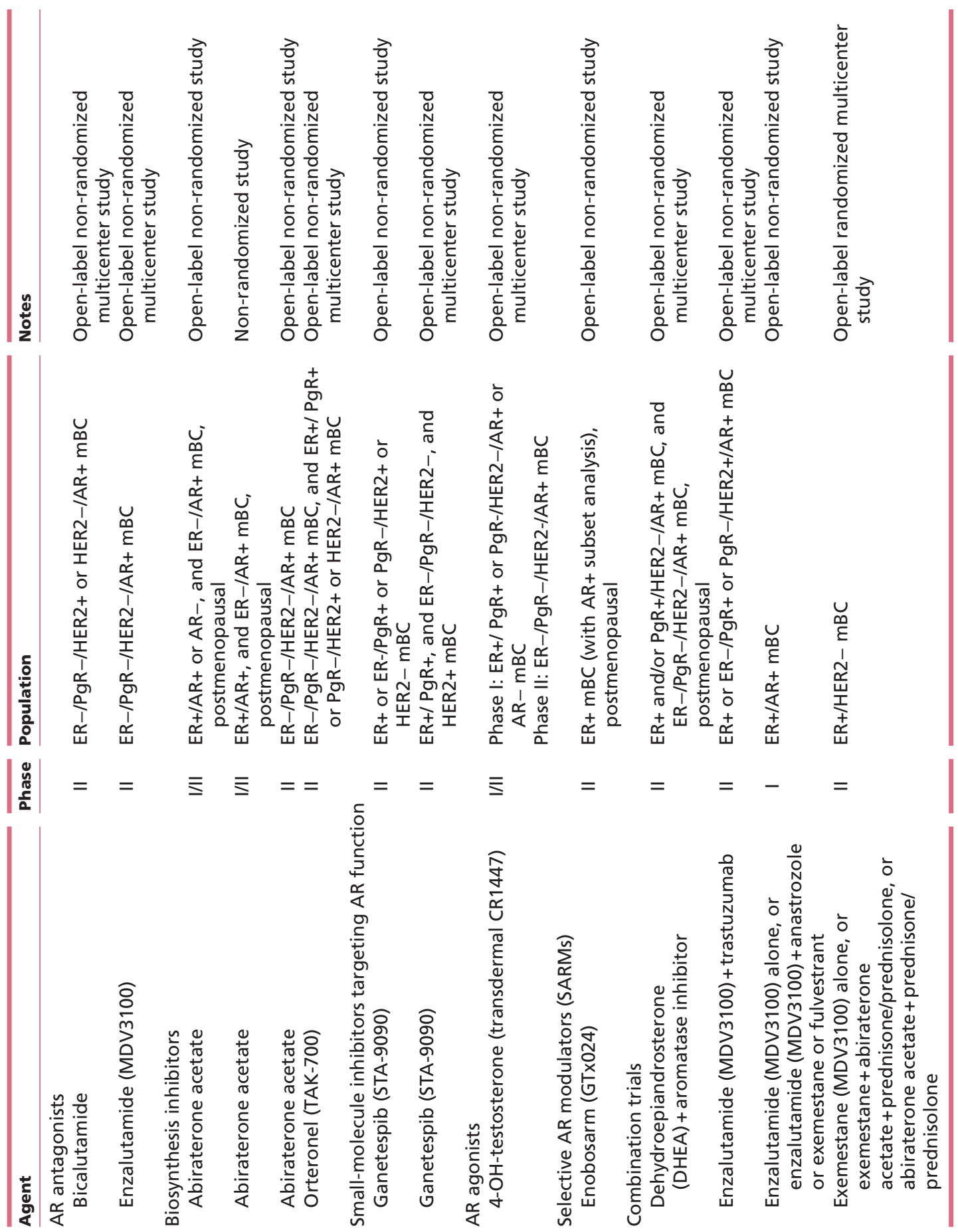


\section{AR and prostate cancer: a source of potential biomarkers for BC}

AR has been extensively studied in prostate cancer, revealing numerous aspects of a complex genetic landscape and providing additional information to aid the evaluation of treatment response and prognosis in prostate tumor. Several biological findings on the role of $\mathrm{AR}$ gene in prostate cancer can be transferred to $\mathrm{BC}$, increasing the number of predictive and prognostic biomarkers for the latter tumor, especially in a specific subset of patients.

The analysis of DNA released by tumor cells into the blood offers the opportunity of identifying circulating biomarkers through an approach commonly called noninvasive 'liquid biopsy' (Crowley et al. 2013, Murtaza et al. 2013). In prostate cancer, AR overexpression and point mutations in the AR LBD detected in cell-free DNA have been demonstrated as drivers of resistance to AR-directed therapies and prognostic factors. The novel AR gain-of-function mutation was recently confirmed as being involved in the pathogenesis of prostate cancer and is present in more than $30 \%$ of castration-resistant prostate cancer (CRPC) patients, correlating with higher protein expression (Tsao et al. 2012). A recent study (Salvi et al. 2015) on 53 consecutive patients with CRPC investigated copy number variations of AR genes using Taqman copy number assays in serum cell-free DNA collected before starting abiraterone. The median progressionfree survival of patients with AR gene gain was 2.8 vs 9.5 months for those without AR gene gain $(P<0.0001)$, whereas the median OS was 5.0 months for the former and 21.9 months for the latter $(P<0.0001)$. Similarly, two other studies (Carreira et al. 2014, Romanel et al. 2015) showed that AR copy number gain, analyzed by nextgeneration sequencing, was associated with resistance to abiraterone in CRPC patients.

Point mutations within the AR LBD have also been implicated in the development of resistance to enzalutamide (F876L, F877L) and abiraterone (T878A and L702H) (Joseph et al. 2013, Korpal et al. 2013, Carreira et al. 2014, Azad et al. 2015, Romanel et al. 2015).

Constitutively active ligand-independent AR splice variants (AR-Vs) that lack the LBD but retain transcriptional activity have been linked to CRPC and resistance to new hormonal therapies. A prospective biomarker study of 62 patients suggested that the presence of AR-V7 (the most abundant AR-V) at the mRNA level in circulating tumor cells predicted a lack of PSA response to abiraterone and enzalutamide and correlated with shorter survival
(Antonarakis et al. 2014). In BC, the growth-promoting activity of AR-V7 has been already explored. Hickey et al. reported that the AR gene produces a diverse range of AR-Vs transcripts in primary breast tumors. In particular, AR-V7 expression is increased in an ER $\alpha$-negative $\mathrm{BC}$ context and is predictive of poorer survival in women with HER2+ disease (Hickey et al. 2015). These authors also provided ex vivo evidence of an AR-V7 upregulation by enzalutamide in primary $\mathrm{BC}$, raising some doubts about the use of anti-androgens in BC.

In the past few years, the presence of singlenucleotide polymorphisms of AR gene has also been investigated in breast and prostate cancers as a further predictor of disease aggressiveness and clinical outcome. In particular, variations in CAG repeat length are associated with prognosis in prostate cancer, where CAG repeats cause altered AR transcriptional activity, influencing prognosis (Salvi et al. 2016). Some authors report that CAG repeat length is also associated with BC prognosis (Cogliati et al. 2015, Lee et al. 2015) and risk (Mao et al. 2015), but prospective studies are needed to confirm these results.

The presence of genomic alterations of AR has also been related to the expression of other receptors, such as the GR. Recent data showed the emergence of functionally active AR mutations in CRPC patients receiving exogenous glucocorticoids, usually correlated with clinical progression on abiraterone or enzalutamide (Carreira et al. 2014). Consequently, caution is needed when administering steroids with hormonal drugs in breast and prostate cancers because the effects of GR activity on tumor cell biology are dependent on concomitant ER and AR activity, underlining the intricate network of AR with other molecular pathways.

Current findings demonstrate the translational relevance of studies on circulating DNA as a tool for monitoring complex clone dynamics and genomic causes of treatment resistance in prostate cancer. Some of these genomic aberrations of AR could also be useful in BC diagnosis and treatment decisions.

The relevance of AR mutations mentioned above is still quite unclear, in prostate cancer and even more in BC. Recent data regarding the presence of $\mathrm{AR}$ mutations in $\mathrm{BC}$ show that they are uncommon and that their functional significance has not been yet demonstrated (Gucalp et al. 2016). Further investigations are warrant in order to define the function of mutations in disease development and during hormonal treatment with androgens or antiandrogens, as well as potential combination treatments aimed at overcoming resistance.

Published by Bioscientifica Ltd. 


\section{Conclusions}

Preclinical and clinical studies are defining the role of AR-targeting treatment in the management of BC.

This role is likely to be different in distinct biological and clinical scenarios.

AR-targeting treatment potentially represents a new target therapy in a subset of ER-negative/PgR-negative breast tumors, until now defined as hormone-insensitive and an additional hormonal treatment option in ER/ PgR-positive tumors. It is further being developed in combination with other specific pathway inhibitors in HER2-positive AR-positive BC patients.

Both AR antagonists and AR agonists will likely become useful and safe options of treatment in various $\mathrm{BC}$ subtypes, but only the ongoing and future prospective clinical trials will allow us to establish which agents are the best options in every specific condition. They will likely be used initially as advanced lines of treatment, after at least one line of anti-estrogen therapy in ER-positive tumors and after chemotherapy in ER-negative tumors. Future studies should address their relative efficacy, compared with anti-estrogen agents, based on the levels of expression of AR and ER in each tumor, as well as their optimal sequencing with anti-estrogen treatments, and their potential use as first-line therapy in selected LAR or AR/ HER2-positive tumors, with low proliferating index, in combination with other targeted agents. Neoadjuvant and pharmacodynamic preoperative studies could be useful to define predictive biomarkers of single agents and drug combinations and to define the worthiness to explore their use in the adjuvant setting.

New androgen agonists without the virilizing side effects of testosterone might prove useful in some AR-positive/ER-positive tumors, whereas AR antagonists could have a role particularly in triplenegative/AR-positive tumors and, in combination with anti-HER2 agents or with other signally pathways inhibitors (including PI3K/MYC/ERK) in HER2-positive/ AR-positive tumors.

Anyway, based on opposite data regarding androgens and AR agonist/antagonist drug effects on cell proliferation in particular in AR-positive/ER-positive tumors, prospective studies administering anti-androgens in this subtype of BC patients should be tested.

\section{Declaration of interest}

The authors declare that there are no conflicts of interest that could be perceived as prejudicing the impartiality of this review.

\section{Funding}

This project was partially funded by the Italian Ministry of Health (project code GR-2009-1594885).

\section{Acknowledgements}

The authors thank Cristiano Verna for editorial assistance.

\section{References}

Antonarakis ES, Lu C, Wang H, Luber B, Nakazawa M, Roeser JC, Chen Y, Mohammad TA, Chen Y, Fedor HL, et al. 2014 AR-V7 and resistance to enzalutamide and abiraterone in prostate cancer. New England Journal of Medicine 371 1028-1038. (doi:10.1056/ NEJMoa1315815)

Arce-Salinas C, Riesco-Martinez MC, Hanna W, Bedard P \& Warner E 2016 Complete response of metastatic androgen receptor-positive breast cancer to bicalutamide: case report and review of the literature. Journal of Clinical Oncology 34 e21-e24. (doi:10.1200/ JCO.2013.49.8899)

Asano Y, Kashiwagi S, Onoda N, Kurata K, Morisaki T, Noda S, Takashima T, Ohsawa M, Kitagawa S \& Hirakawa K 2016 Clinical verification of sensitivity to preoperative chemotherapy in cases of androgen receptor-expressing positive breast cancer. British Journal of Cancer 114 14-20. (doi:10.1038/bjc.2015.434)

Asghar U, Herrera-Abreu MT, Cutts R, Babina I, Pearson A \& Turner NC 2015 Identification of subtypes of triple negative breast cancer (TNBC) that are sensitive to CDK4/6 inhibition. Journal of Clinical Oncology 33 (Supplement) 11098.

Azad AA, Volik SV, Wyatt AW, Haegert A, Le Bihan S, Bell RH, Anderson SA, McConeghy B, Shukin R, Bazov J, et al. 2015 Androgen receptor gene aberrations in circulating cell-free DNA: biomarkers of therapeutic resistance in castration-resistant prostate cancer. Clinical Cancer Research 21 2315-2324. (doi:10.1158/1078-0432.CCR-142666)

Barton VN, D'Amato NC, Gordon MA, Lind HT, Spoelstra NS, Babbs BL, Heinz RE, Elias A, Jedlicka P, Jacobsen BM, et al. 2015 Multiple molecular subtypes of triple-negative breast cancer critically rely on androgen receptor and respond to enzalutamide in vivo. Molecular Cancer Therapy 14 769-778. (doi:10.1158/15357163.MCT-14-0926)

Billich A, Nussbaumer P \& Lehr P 2000 Stimulation of MCF-7 breast cancer cell proliferation by estrone sulfate and dehydroepiandrosterone sulfate: inhibition by novel non-steroidal steroid sulfatase inhibitors. Journal of Steroid Biochemistry and Molecular Biology 73 225-235. (doi:10.1016/S09600760(00)00077-7)

Birrell SN, Bentel JM, Hickey TE, Ricciardelli C, Weger MA, Horsfall DJ \& Tilley WD 1995 Androgens induce divergent proliferative responses in human breast cancer cell lines. Journal of Steroid Biochemistry and Molecular Biology 52 459-467. (doi:10.1016/0960-0760(95)00005-K)

Boccuzzi G, Brignardello E, di Monaco M, Forte C, Leonardi L \& Pizzini A 1992 Influence of dehydroepiandrosterone and 5-en-androstene-3 beta, 17 beta-diol on the growth of MCF-7 human breast cancer cells induced by 17 beta-estradiol. Anticancer Research 12 799-803.

Boni C, Pagano M, Panebianco M, Bologna A, Sierra NM, Gnoni R, Formisano D \& Bisagni G 2014 Therapeutic activity of testoterone in metastatic breast cancer. Anticancer Research 34 1287-1290.

Carreira S, Romanel A, Goodall J, Grist E, Ferraldeschi R, Miranda S, Prandi D, Lorente D, Frenel JS, Pezaro C, et al. 2014 Tumor clone dynamics in lethal prostate cancer. Science Translational Medicine 6 254ra125. (doi:10.1126/scitranslmed.3009448) 
Chia KM, Liu J, Francis GD \& Naderi A 2011 A feedback loop between androgen receptor and ERK signaling in estrogen receptor-negative breast cancer. Neoplasia 13 154-166. (doi:10.1593/neo.101324)

Chia K, O’Brien M, Brown M \& Lim E 2015 Targeting the androgen receptor in breast cancer. Current Oncology Reports 17 4. (doi:10.1007/ s11912-014-0427-8)

Choi JE, Kang SH, Lee SJ \& Bae YK 2015 Androgen receptor expression predicts decreased survival in early stage triple-negative breast cancer. Annals of Surgical Oncology 22 82-89. (doi:10.1245/s10434014-3984-z)

Cochrane DR, Bernales S, Jacobsen BM, Cittelly DM, Howe EN, D'Amato NC, Spoelstra NS, Edgerton SM, Jean A, Guerrero J, et al. 2014 Role of the androgen receptor in breast cancer and preclinical analysis of enzalutamide. Breast Cancer Research 16 R7. (doi:10.1186/ bcr3599)

Cogliati P, Ciniselli CM, Agresti R, Paolini B, Bonini C, Radice P, Krogh V, Verderio P \& Venturelli E 2015 Androgen receptor CAG repeat length and estrogen receptor status in postmenopausal breast cancer prognosis. International Journal of Biological Markers 30 e418- e424. (doi:10.5301/jbm.5000176)

Coss CC, Jones A \& Dalton JT 2014 Selective androgen receptor modulators as improved androgen therapy for advanced breast cancer. Steroids 90 94-100. (doi:10.1016/j.steroids.2014.06.010)

Crowley E, Di Nicolantonio F, Loupakis F \& Bardelli A 2013 Liquid biopsy: monitoring cancer-genetics in the blood. Nature Reviews Clinical Oncology 10 472-484. (doi:10.1038/nrclinonc.2013.110)

De Amicis F, Thirugnansampanthan J, Cui Y, Selever J, Beyer A, Parra I, Weigel NL, Herynk MH, Tsimelzon A, Lewis MT, et al. 2010 Androgen receptor overexpression induces tamoxifen resistance in human breast cancer cells. Breast Cancer Research and Treatment 121 1-11. (doi:10.1007/s10549-009-0436-8)

Fels E 1944 Treatment of breast cancer with testosterone propionate. Journal of Clinical Endocrinology and Metabolism 4 I21.

Fioretti FM, Sita-Lumsden A, Bevan CL \& Brooke GN 2014 Revising the role of the androgen receptor in breast cancer. Journal of Molecular Endocrinology 52 R257-R265. (doi:10.1530/JME-14-0030)

Frank E \& Heeemann J 1946 The use of testosterone propionate in treatment of advanced carcinoma of the brest. Annals of Surgery 123 1023-1035. (doi:10.1097/00000658-194606000-00006)

Glaser R \& Dimitrakakis C 2015 Testosterone and breast cancer prevention. Maturitas 82 291-295. (doi:10.1016/j. maturitas.2015.06.002)

Goldenberg IS 1964 Testosterone propionate therapy in breast cancer JAMA 188 1069-1072. (doi:10.1001/jama.1964.03060380037009)

Goldenberg IS, Waters N, Ravdin RS, Ansfield FJ \& Segaloff A 1973 Androgenic therapy for advanced breast cancer in women. A report of the cooperative breast cancer group. JAMA 223 1267-1268. (doi:10.1001/jama.1973.03220110045012)

Gordan GS, Halden A, Horn Y, Fuery JJ, Parsons RJ \& Walter RM 1973 Calusterone (7beta,17alpha-dimethyltestosterone) as primary and secondary therapy of advanced breast cancer. Oncology 28 138-146. (doi:10.1159/000224811)

Gucalp A, Tolaney S, Isakoff SJ, Ingle JN, Liu MC, Carey LA, Blackwell K, Rugo H, Nabell L, Forero A et al. 2013 Translational Breast Cancer Research Consortium (TBCRC 011). Phase II trial of bicalutamide in patients with androgen receptor-positive, estrogen receptor-negative metastatic breast cancer. Clinical Cancer Research 19 5505-5512. (doi:10.1158/1078-0432.CCR-12-3327)

Gucalp A, Proverbs-Singh TA, Razavi P, Chandarlapaty S, Patil S, Ross DS, Zehir A, Baselga J, Hudis CA \& Traina TA 2016 Androgen receptor (AR) mutations in a cohort of patients with breast cancer (BC) who have undergone tumor genomic profiling. Cancer Research 76 P6-07-08. (doi:10.1158/1538-7445.SABCS15-P6-07-08)

Heinlein CA \& Chang C 2002 The roles of androgen receptors and androgen-binding proteins in nongenomic androgen actions. Molecular Endocrinology 16 2181-2187. (doi:10.1210/me.2002-0070)
Hickey TE, Irvine CM, Dvinge H, Tarulli GA, Hanson AR, Ryan NK, Pickering MA, Birrell SN, Hu DG, Mackenzie PI, et al. 2015 Expression of androgen receptor splice variants in clinical breast cancers. Oncotarget 6 44728-44744. (doi:10.18632/oncotarget.6296)

Higa GM \& Fell RG 2013 Sex hormone receptor repertoire in breast cancer. International Journal of Breast Cancer 2013284036. (doi:10.1155/2013/284036)

Hilborn E, Gacic J, Fornander T, Nordenskjöld B, Stål O \& Jansson A 2016 Androgen receptor expression predicts beneficial tamoxifen response in oestrogen receptor- $\alpha$-negative breast cancer. British Journal of Cancer 114 248-255. (doi:10.1038/bjc.2015.464)

International Breast Cancer Study Group, Colleoni M, Gelber S, Goldhirsch A, Aebi S, Castiglione-Gertsch M, Price KN, Coates AS \& Gelber RD 2006 Tamoxifen after adjuvant chemotherapy for premenopausal women with lymph node-positive breast cancer: International Breast Cancer Study Group Trial 13-93. Journal of Clinical Oncology 24 1332-1341. (doi:10.1200/JCO.2005.03.0783)

Jiang M, Ma Y, Chen C, Fu X, Yang S, Li X, Yu G, Mao Y, Xie Y \& Li Y 2009 Androgen-responsive gene database: integrated knowledge on androgen-responsive genes. Molecular Endocrinology 23 1927-1933. (doi:10.1210/me.2009-0103)

Joseph JD, Lu N, Qian J, Sensintaffar J, Shao G, Brigham D, Moon M, Maneval EC, Chen I, Darimont B, et al. 2013 A clinically relevant androgen receptor mutation confers resistance to second-generation antiandrogens enzalutamide and ARN-509. Cancer Discovery 3 1020-1029. (doi:10.1158/2159-8290.CD-13-0226)

Kach J, Conzen SD \& Szmulewitz RZ 2015 Targeting the glucocorticoid receptor in breast and prostate cancers. Science Translation Medicine $\mathbf{7}$ 305ps19. (doi:10.1126/scitranslmed.aac7531.)

Kennedy BJ 1958 Fluoxymesterone therapy in advanced breast cancer. New England Journal of Medicine 259 673-675. (doi:10.1056/ NEJM195810022591404)

Kim Y, Jae E \& Yoon M 2015 Influence of androgen receptor expression on the survival outcomes in breast cancer: a meta-analysis. Journal of Breast Cancer 18 134-142. (doi:10.4048/jbc.2015.18.2.134)

Korpal M, Korn JM, Gao X, Rakiec DP, Ruddy DA, Doshi S, Yuan J, Kovats SG, Kim S, Cooke VG, et al. 2013 An F876L mutation in androgen receptor confers genetic and phenotypic resistance to MDV3100 (enzalutamide). Cancer Discovery 3 1030-1043. (doi:10.1158/2159-8290)

Koryakina Y, Ta HQ \& Gioeli D 2014 Androgen receptor phosphorylation: biological context and functional consequences. Endocrine-Related Cancer 21 T131-T145. (doi:10.1530/ERC-13-0472)

Kumar R \& McEwan IJ 2012 Allosteric modulators of steroid hormone receptors: structural dynamics and gene regulation. Endocrine Reviews 33 271-299. (doi:10.1210/er.2011-1033)

Lanzino M, Sisci D, Morelli C, Garofalo C, Catalano S, Casaburi I, Capparelli C, Giordano C, Giordano F, Maggiolini M, et al. 2010 Inhibition of cyclin D1expression by androgen receptor in breast cancer cells - identification of a novel androgen response element. Nucleic Acids Research 38 5351-5365. (doi:10.1093/nar/gkq278)

Lee YT, Liu HM, Lee LH, Liu CJ, Lin JS, Chao TC, Tzeng WF \& Chiou TJ 2015 The polymorphism of CAG repeats in the androgen receptor gene and breast cancer mortality. Cancer Biomarkers 15 815-822. (doi:10.3233/CBM-150525)

Lehmann BD, Bauer JA, Chen X, Sanders ME, Chakravarthy AB, Shyr Y \& Pietenpol JA 2011 Identification of human triple-negative breast cancer subtypes and preclinical models for selection of targeted therapies. Journal of Clinical Investigation 121 2750-2767. (doi:10.1172/JCI45014)

Li J \& Al-Azzawi F 2009 Mechanism of androgen receptor action. Maturitas 63 142-148. (doi:10.1016/j.maturitas.2009.03.008)

Liao RS, Ma S, Miao L, Li R, Yin Y \& Raj GV 2013 Androgen receptormediated non-genomic regulation of prostate cancer cell proliferation. Translational Andrology and Urology 2 187-196. (doi:10.3978/j.issn.2223-4683.2013.09.07) 
Lim E, Ni M, Hazra A, Tamimi R \& Brown M 2012 Elucidating the role of androgen receptor in breast cancer. Journal of Clinical Investigation 2 1003-1011. (doi:10.1158/1078-0432)

Lim E, Ni M, Cao S, Hazra A, Tamimi RM \& Brown M 2014 Importance of breast cancer subtype in the development of androgen receptor directed therapy. Current Breast Cancer Reports 6 71-78. (doi:10.1007/ s12609-014-0140-5)

Loeser A 1939 Male Hormone in the treatment of cancer of the breast. Unio Internationalis Contra Cancrum 4 375-384.

Loibl S, Müller BM, von Minckwitz G, Schwabe M, Roller M, Darb-Esfahani S, Ataseven B, du Bois A, Fissler-Eckhoff A, Gerber B, et al. 2011 Androgen receptor expression in primary breast cancer and its predictive and prognostic value in patients treated with neoadjuvant chemotherapy. Breast Cancer Research and Treatment 130 477-487. (doi:10.1007/s10549-011-1715-8)

Maggiolini M, Donzé O, Jeannin E, Andò S \& Picard D 1999 Adrenal androgens stimulate the proliferation of breast cancer cells as direct activators of estrogen receptor alpha. Cancer Research 59 4864-4869.

Mangelsdorf DJ, Thummel C, Beato M, Herrlich P, Schütz G, Umesono K, Blumberg B, Kastner P, Mark M, Chambon P, et al. 1995 The nuclear receptor superfamily: the second decade. Cell $\mathbf{8 3}$ 835-839. (doi:10.1016/0092-8674(95)90199-X)

Mao Q, Qiu M, Dong G, Xia W, Zhang S, Xu Y, Wang J, Rong Y, Xu L \& Jiang F 2015 CAG repeat polymorphisms in the androgen receptor and breast cancer risk in women: a meta-analysis of 17 studies. OncoTargets Therapy 8 2111-2120. (doi:10.2147/OTT.S85130)

Masuda H, Baggerly KA, Wang Y, Zhang Y, Gonzalez-Angulo AM, Meric-Bernstam F, Valero V, Lehmann BD, Pietenpol JA, Hortobagyi GN, et al. 2013 Differential response to neoadjuvant chemotherapy among 7 triple-negative breast cancer molecular subtypes. Clinical Cancer Research 19 5533-5540. (doi:10.1158/10780432.CCR-13-0799)

Murtaza M, Dawson SJ, Tsui DW, Gale D, Forshew T, Piskorz AM, Parkinson C, Chin SF, Kingsbury Z, Wong AS, et al. 2013 Non-invasive analysis of acquired resistance to cancer therapy by sequencing of plasma DNA. Nature 497 108-112. (doi:10.1038/nature12065)

Naderi A 2015 Coagulation factor VII is regulated by androgen receptor in breast cancer. Experimental Cell Research 331 239-250. (doi:10.1016/j.yexcr.2014.10.002)

Nahleh Z 2008 Androgen receptor as a target for the treatment of hormone receptor-negative breast cancer: an unchartered territory. Future Oncology 4 15-21. (doi:10.2217/14796694.4.1.15)

Najid A \& Habrioux G 1990 Biological effects of adrenal androgens on MCF-7 and BT-20 human breast cancer cells. Oncology 47 269-274. (doi:10.1159/000226830)

Ng CHM, Macpherson I, Rea D, Spicer J, Bowman A, Jones A, Dowsett M, Johnston SRD, Dobbs N \& De Bono JS 2012 Phase I/II study of abiraterone acetate (AA) in estrogen receptor (ER) or androgen receptor (AR) positive metastatic breast cancer (MBC). Presented at the European Society for Medical Oncology Congress 2012, Vienna, Austria. Abstract 325PD. (available at: http:// oncologypro.esmo.org/Meeting-Resources/ESMO-2012/Phase-I-II-trialof-abiraterone-acetate-AA-in-estrogen-receptor-ERa-or-androgenreceptor-AR-positive-metastatic-breast-cancer-mBC).

Ni M, Chen Y, Lim E, Wimberly H, Bailey ST, Imai Y, Rimm DL, Liu XS \& Brown M 2011 Targeting androgen receptor in estrogen receptornegative breast cancer. Cancer Cell 20 119-131. (doi:10.1016/j. ccr.2011.05.026.)

Ni M, Chen Y, Fei T, Li D, Lim E, Liu XS \& Brown M 2013 Amplitude modulation of androgen signaling by c-MYC. Genes \& Development 27 734-748. (doi:10.1101/gad.209569.112)

Ocana A, Vera-Badillo F, Templeton A, Tannock I \& Amir E 2015 Response. Journal of the Natlional Cancer Institute 107 djv244. (doi:10.1093/jnci/djv244)

O'Shaughnessy J, Campone M, Brain E, Neven P, Hayes D, Bondarenko I, Griffin TW, Martin J, De Porre P, Kheoh T, et al. 2016
Abiraterone acetate, exemestane or the combination in postmenopausal patients with estrogen receptor-positive metastatic breast cancer. Annals of Oncology 27 106-113. (doi:10.1093/annonc/ mdv487)

Overmoyer B 2015 Enobosarm for the treatment of metastatic, estrogen and androgen receptor positive, breast cancer. Final results of the primary endpoint and current progression free survival. Cancer Research 75 P1-13-04. (doi:10.1158/1538-7445.SABCS14-P1-13-04)

Pang D, Kocherginsky M, Krausz T, Kim SY \& Conzen SD 2006 Dexamethasone decreases xenograft response to Paclitaxel through inhibition of tumor cell apoptosis. Cancer Biology \& Therapy $\mathbf{5}$ 933-940. (doi:10.4161/cbt.5.8.2875)

Park S, Koo JS, Kim MS, Park HS, Lee JS, Lee JS, Kim SI, Park BW \& Lee KS 2011 Androgen receptor expression is significantly associated with better outcomes in estrogen receptor-positive breast cancers. Annals of Oncology 22 1755-1762. (doi:10.1093/annonc/mdq678)

Park S, Park HS, Koo JS, Yang WI, Kim SI \& Park BW 2012 Higher expression of androgen receptor is a significant predictor for better endocrine-responsiveness in estrogen receptor-positive breast cancers. Breast Cancer Research and Treatment 133 311-320. (doi:10.1007/s10549-011-1950-z)

Peters AA, Buchanan G, Ricciardelli C, Bianco-Miotto T, Centenera MM, Harris JM, Jindal S, Segara D, Jia L, Moore NL, et al. 2009 Androgen receptor inhibits estrogen receptor-alpha activity and is prognostic in breast cancer. Cancer Research 69 6131-6140. (doi:10.1007/s10549011-1950-z)

Poulin R \& Labrie F 1986 Stimulation of cell proliferation and estrogenic response by adrenal C19-delta 5-steroids in the ZR-75-1 human breast cancer cell line. Cancer Research 46 4933-4937.

Proverbs-Singh T, Feldman JL, Morris MJ, Autio KA \& Traina TA 2015 Targeting the androgen receptor in prostate and breast cancer: several new agents in development. Endocrine-Related Cancer 22 R87-R106. (doi:10.1530/ERC-14-0543)

Qu Q, Mao Y, Fei XC \& Shen KW 2013 The impact of androgen receptor expression on breast cancer survival: a retrospective study and meta-analysis. PLOS ONE 8 e82650. (doi:10.1371/ journal.pone.0082650)

Rizza P, Barone I, Zito D, Giordano F, Lanzino M, De Amicis F, Mauro L, Sisci D, Catalano S, Dahlman Wright K, et al. 2014 Estrogen receptor beta as a novel target of androgen receptor action in breast cancer cell lines. Breast Cancer Research 16 R21. (doi:10.1186/bcr3619)

Romanel A, Tandefelt DG, Conteduca V, Jayaram A, Casiraghi N, Wetterskog D, Salvi S, Amadori D, Zafeiriou Z, Rescigno P, et al. 2015 Plasma AR and abiraterone-resistant prostate cancer. Science Translation Medicine 7 312re10. (doi:10.1126/scitranslmed.aac9511)

Salvi S, Casadio V, Conteduca V, Burgio SL, Menna C, Bianchi E, Rossi L, Carretta E, Masini C, Amadori D, et al. 2015 Circulating cell-free AR and CYP17A1 copy number variations may associate with outcome of metastatic castration-resistant prostate cancer patients treated with abiraterone. British Journal of Cancer 112 1717-1724. (doi:10.1038/bjc.2015.128)

Salvi S, Conteduca V, Gurioli G, Calistri D, Casadio V \& De Giorgi U 2016 Impact of candidate genetic polymorphisms in prostate cancer: an overview. Molecular Diagnosis \& Therapy 20 1-12. (doi:10.1007/ s40291-015-0169-9)

Segaloff A, Gordon D, Horwitt BN, Schlosser JV \& Murison PJ 1951 Hormonal therapy in cancer of the breast. I. the effect of testosterone propionate therapy on clinical course and hormonal excretion. Cancer 4 319-323. (doi:10.1002/10970142(195103)4:2<319::AID-CNCR2820040217>3.0.CO;2-5)

Simoncini T \& Genazzani AR 2003 Non-genomic actions of sex steroid hormones. European Journal of Endocrinology 148 281-292. (doi:10.1530/eje.0.1480281)

Traina TA, Miller K, Yardley DA, O'Shaughnessy J, Cortes J, Awada A, Kelly CM, Trudeau ME, Schmid P, Gianni L, et al. 2015 Results from a phase 2 study of enzalutamide (ENZA), an androgen receptor (AR) http://erc.endocrinology-journals.org

DOI: 10.1530/ERC-16-0190
๑) 2016 Society for Endocrinology Printed in Great Britain 
inhibitor, in advanced AR+ triple-negative breast cancer (TNBC). Journal of Clinical Oncology 33 (Supplement).

Tran C, Ouk S, Clegg NJ, Chen Y, Watson PA, Arora V, Wongvipat J, Smith-Jones PM, Yoo D, Kwon A, et al. 2009 Development of a second-generation antiandrogen for treatment of advanced prostate cancer. Science 324 787-790. (doi:10.1126/science.1168175)

Tsao CK, Galsky MD, Small AC, Yee T \& Oh WK 2012 Targeting the androgen receptor signalling axis in castration-resistant prostate cancer (CRPC). BJU International 110 1580-1588.

(doi:10.1111/j.1464-410X.2012.11445.x)

Ulrich P 1939 Testosterone (Hormone Male) et son R6le possible dans le Traitment de Certains Cancers du Sein. Unio Internationalis Contra Cancrum 4377.
Vera-Badillo FE, Templeton AJ, de Gouveia P, Diaz-Padilla I, Bedard PL, Al-Mubarak M, Seruga B, Tannock IF, Ocana A \& Amir E 2014 Androgen receptor expression and outcomes in early breast cancer: a systematic review and meta-analysis. Journal of the National Cancer Institute 106 djt319. (doi:10.1093/jnci/djt319)

Wang Y \& Yang H 2015 RE: androgen receptor expression and outcomes in early breast cancer: a systematic review and metaanalysis. Journal of the National Cancer Institute 107 (doi:10.1093/ jnci/djv241).

Zhu J, Blenis J \& Yuan J 2008 Activation of PI3K/Akt and MAPK pathways regulates Myc-mediated transcription by phosphorylating and promoting the degradation of Mad1. PNAS 105 6584-6589. (doi:10.1073/pnas.0802785105)

Received in final form 11 August 2016

Accepted 12 August 2016

Accepted Preprint published online 15 August 2016
Published by Bioscientifica Ltd. 